\title{
Frontiers in Osteoarthritis: Executive Summary of the Scientific Meeting
}

\author{
Steven Goldring, M.D. • Timothy Wright, Ph.D.
}

Received: 31 August 2011/Accepted: 24 October 2011/Published online: 4 February 2012

(C) Hospital for Special Surgery 2012

Osteoarthritis (OA) is the most common form of arthritis and represents the leading cause of disability in the USA. Importantly, with an aging population, the prevalence, impact, and economic consequences of OA will rise dramatically within the next decades. Although much has been learned concerning the factors that play a role in the initiation and progression of OA, this information has not been effectively translated into individual or public health strategies that have significantly altered the natural history of this disabling form of arthritis. While total joint arthroplasty is an effective treatment for the late stages of OA, no validated pharmacologic interventions exist for effectively eliminating pain and restoring function during disease progression.

Although initially regarded as a disease of articular cartilage, numerous lines of investigation have established that OA represents an example of total "organ failure," in which every component of the joint tissues, including the cartilage, synovium, periarticular bone, and connective tissues, is affected by the disease process. Given OA's pleiotropic effects on joint tissues, the development of effective diagnostic, preventative, and treatment strategies requires a broad interdisciplinary approach that embraces multiple scientific and public health disciplines. This need formed the basis for the sponsorship of the "Osteoarthritis Summit: Frontiers in OA Research, Prevention, and Care" that was held at the Hospital for Special Surgery in New York in June, 2011, the results of which are published in this issue of the HSS Journal.

\footnotetext{
S. Goldring M.D. $\cdot$ T. Wright Ph.D. $(\bowtie)$

Hospital for Special Surgery,

535 East 70th Street, New York, NY 10021, USA

e-mail:wrightt@hss.edu

S. Goldring M.D. · T. Wright Ph.D.

Weill Cornell Medical College, New York, NY 10065, USA
}

The Osteoarthritis Summit brought together research scientists; clinicians caring for patients with OA; governmental officials responsible for aiding and directing research; representatives from major OA research societies and foundations; and members of the pharmaceutical, device, and insurance industries in a workshop setting (Fig. 1). The meeting was organized into a series of six sessions that included concise presentations from the meeting attendees. Each session focused on a specific aspect of OA, progressing from an overview of the clinician's perspective and the classification and epidemiology of OA to a session on pathological and pathogenic processes in OA, including structural alterations and the onset and characterization of symptoms. The third session focused on the diagnosis and assessment of OA, while the fourth centered on strategies for OA prevention. The fifth and sixth sessions covered current treatments for $\mathrm{OA}$ and identified opportunities and priorities for development of future therapies and public health strategies. The formal presentations were followed by extended breakout sessions that provided an open forum for discussion of perspectives that addressed critical questions related to $\mathrm{OA}$ with the goal of reaching consensus on the current state of knowledge of OA research and the strategies for OA diagnosis, prevention, and treatment.

Disclosures Each author certifies that he or she has no commercial associations (e.g., consultancies, stock ownership, equity interest, patent/licensing arrangements, etc.) that might pose a conflict of interest in connection with the submitted article. 


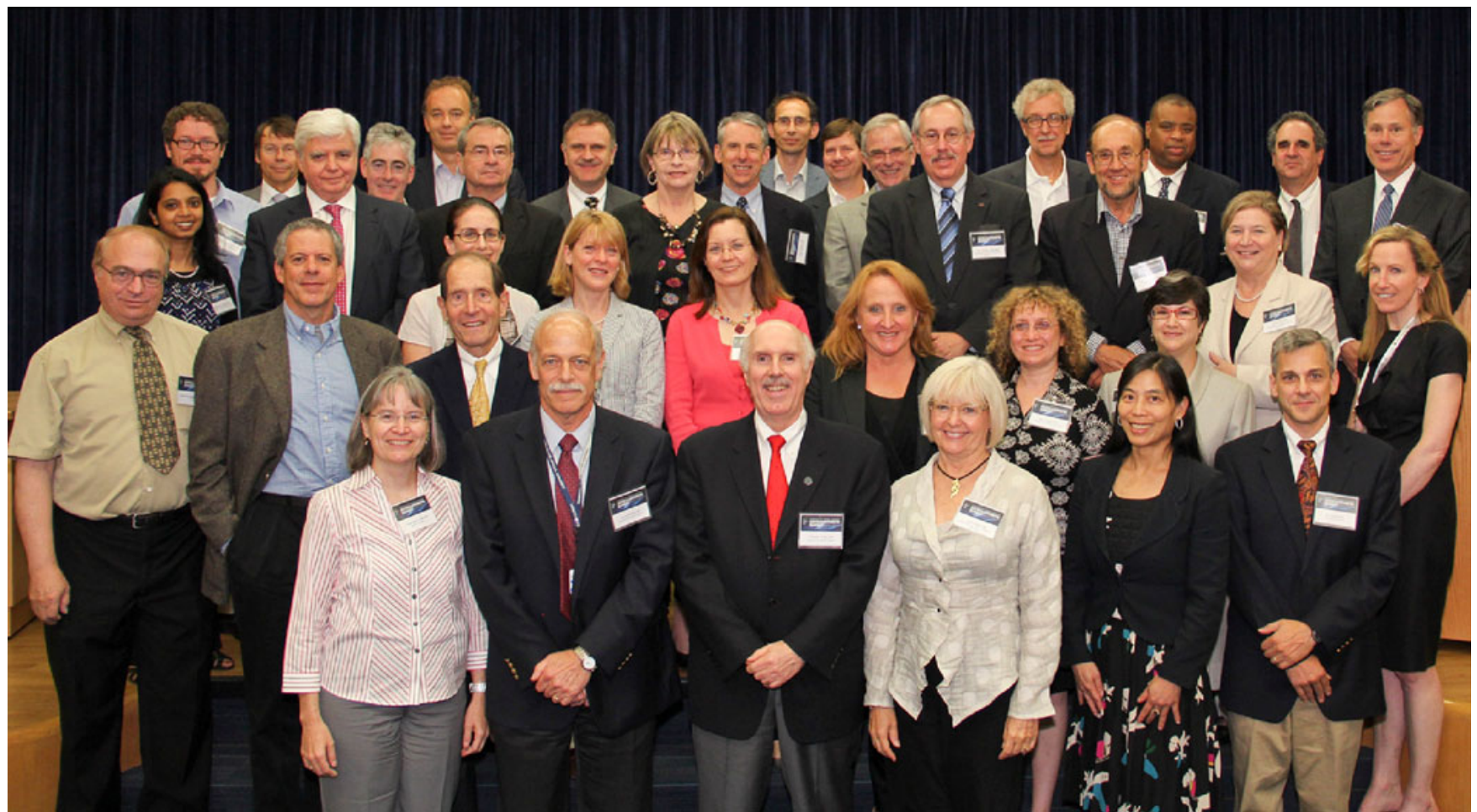

Fig. 1. Participants of the Osteoarthritis Summit: Frontiers in OA Research, Prevention, and Care. Courtesy of Hospital for Special Surgery.

Bottom row (left to right): Virginia Kraus, MD, PhD; Steven Goldring, MD; Timothy Wright, PhD; Linda Sandell, MD; Constance Chu, MD; BJ Fregly, PhD.

Middle row: Randall Krakauer, MD; Howard Seeherman, PhD; Victor Goldberg, MD; Lisa Mandl, Md; Gillian Hawker, MD, MSc, FRCPC; Joanne Jordan, MD, MPH; Lynn Snyder-Mackler, PT, Sc.D, MS; Elena Losina, PhD; Carla Scanzello, MD, PhD; Gayle Lester, MD; Hollis Potter, MD.

Top row: Tuhina Neogi, MD; Stephen Lyman, PhD; Bruce Kidd, MD; Thomas Sculco, MD; Stephen Messier, PhD; David Hunter, PhD; Joseph Buckwalter, MD; Steven Olson, MD; Mary Goldring, PhD; Timothy McAlindon, MD; Harrie Weinans, PhD; Richard Loeser, MD; John Hardin, MD; Marc Hochberg, MD; Stefan Lohmander, MD; Robin Poole, PhD; Michael Parks, MD; Jeffrey Katz, MD, John Callaghan, MD 